\title{
A Luta das Pescadoras Artesanais da Ilha de Maré em Defesa do seu Território
}

\author{
Fátima Cristina Cunha Maia Silva ${ }^{a}$ \\ Julia Figueredo Benzaquen ${ }^{b}$ \\ Ana Maria Dubeux Gervais ${ }^{c}$ \\ Jorge Luiz Schirmer de Mattos ${ }^{d}$
}

\begin{abstract}
Resumo: $\mathrm{O}$ objetivo deste estudo foi refletir sobre o protagonismo das pescadoras artesanais da Ilha de Maré, localizada na Baia de Todos-os-Santos, pertencente ao município de Salvador - BA. A luta em defesa do seu território e dos direitos a um ambiente saudável, condições de trabalho e qualidade de vida se passa num cenário hostil, em decorrência da exposição ao complexo portuário e industrial de Aratu. Isso nos remeteu a uma abordagem a luz da decolonialização da população das águas, utilizando-nos de uma metodologia baseada na pesquisa-ação, no levantamento bibliográfico e nos diálogos com as mulheres das águas.

Palavras-chaves: Decolonialidade, Direitos, Lutas sociais, Mulheres das águas.
\end{abstract}

"Para descolonizarmos o conhecimento, precisamos nos ater à identidade social, não somente para evidenciar como o projeto de colonização tem criado essas identidades, mas para mostrar como certas identidades têm sido historicamente silenciadas" (Ribeiro 2017:29).

a Doutoranda do Programa de Pós-Graduação e Desenvolvimento Territorial (UFRPE). Email: fcristinamaia@gmail.com.

b Professora Convidada do Programa de Pós-Graduação e Desenvolvimento (UFRPE). Email: julia.benzaquen@ufrpe.br.

c Vice-Coordenadora do Programa de Pós-Graduação e Desenvolvimento (UFPE). Email: anabubeux66@gmail.com.

d Coordenador do Programa de Pós-Graduação e Desenvolvimento Territorial (UFPE). Email: jorge.mattos@ufrpe.br. 
Este trabalho busca refletir sobre a luta por direitos sociais, econômicos, políticos, ambientais protagonizada pelas pescadoras artesanais da Baia de Todos-os-Santos (BTS), em especial, da Ilha de Maré, Salvador - BA. Partimos, então, da seguinte premissa: se a pesca artesanal garante a segurança alimentar e nutricional de uma parcela significativa da sociedade, por que as denúncias de injustiça ambiental no território das pescadoras não são levadas em consideração e suas reivindicações atendidas? Por que elas não são escutadas? E em meio a tanto descaso, parafraseando Spivak cabe indagar: "Pode o subalterno ${ }^{1}$ [sic] falar?" (2010:19).

Segundo Antonio Gramsci, a ideia de classe subalterna [sic passim] se encontra sob a visão de mundo das classes dominantes. Inclui as associações de moradores, trabalhadores informais, movimentos urbanos e rurais, entre outros, como elemento de grupos sociais organizados ou não na estrutura do capitalismo. Explicita Gramsci que os grupos subalternizados, por um lado, sofrem sempre a iniciativa dos grupos dominantes, mesmo quando se rebelam (Gramsci 1977:96). Assim, é essencial que a classe forje sua própria identidade, valores, seu modo de vida.

O conceito de 'subalterno' assume assim, diversos significados, inclusive imposto pelo colonialismo, que é um elemento da situação de explorados, pois sofrem com as iniciativas da classe dominante, e consequentemente levando, em especial, as populações da pesca artesanal a resistência, pois impactam diretamente no modo de vida e de reprodução social dessa população.

Refletindo o que os autores Harkot-de-la-Taille \& Santos (2012) trazem, e fazendo uma analogia, optamos pelo termo subalternizado, pois a palavra subalterno dá uma ideia de impotência das populações tradicionais na luta por seus direitos e retomada de seus modos de vida, ao passo que a palavra 'subalternizados' demonstra que eles vão além dos processos de dominação. Ademais, os percursos empreendidos até aqui para citar como exemplo, configuram resistência, 'manifestações sociais de luta', visando uma sociedade mais justa, menos desigual e livre da opressão. 
É importante compreender como esses processos de dominação acontecem, pois impactam na subjetividade e na emancipação do sujeito. Por outro lado, o Estado anula autonomias das classes subalternizadas, pois "[...] a ditadura contemporânea, ao mesmo tempo em que suprime algumas formas de autonomia de classe, também se empenha em incorporá-las na atividade estatal, isto é, a centralidade de toda a vida nacional paira nas mãos das classes dominantes" (Gramsci 1977:303). Cabe destacar que Achille Mbembe (2018) explicita como o sujeito negro começa a situar no mundo, onde o Estado deixa viver e faz morrer, vai pautar a soberania do Estado, onde este, legitima o monopólio de poder por grupos específicos.

$\mathrm{Na}$ contramão dessa lógica perversa surge em 2005 a instituição da Articulação Nacional de Pescadoras (ANP), presente hoje em 18 estados brasileiros, com objetivo de articular as mulheres das águas (de beiras de rios, lagoas, praias) fortalecendo-as e empoderando-as para o enfrentamento do racismo, do machismo, para defenderem seus territórios, lutarem para a garantia dos seus direitos e provocarem a formulação de outras políticas públicas voltadas às populações das águas. A criação da ANP, ao expressar seus princípios de harmonia com a natureza e lutar por seus direitos torna evidente que as 'de baixo', de forma organizada podem à sua maneira ir rompendo com as amarras da condição de subalternizadas.

Contudo, não se trata de uma tarefa fácil, pois há que se ter em conta que o processo de colonização brasileira impôs desde o início um sistema complexo, de cosmologia ocidental, cuja visão particular das relações entre ser humano e natureza tinha como base os interesses teológicos e da corte. A terra, o solo e tudo aquilo que dele crescesse se transformava em mercadoria a partir de um novo sistema epistemológico, no qual a natureza era vista sob uma lógica de produtos agrícolas e de extração maciça de recursos naturais.

Essa visão, apresentava-se como um confronto face ao jeito diferente de 'ler o mundo' (Freire 1989) dos povos originários, sabedores da necessidade da preservação do ambiente e de formas de manejo 
dos recursos naturais que têm se mostrado relevantes para a preservação e reprodução deste ambiente.

Assim, a ação do ser humano sobre o meio ambiente tem se tornado cada vez mais insustentável, razão pela qual, torna-se necessária a construção de uma nova relação entre o ser humano e a natureza, bem como a necessidade de reflexão sobre as manifestações culturais que estão inseridas neste contexto, buscando, inclusive, diminuir as iniquidades sociais provenientes destas relações. Essas últimas têm gerado crises ambientais profundas e, em certos casos, irreversíveis. Como exemplos, podemos citar a degradação da biodiversidade, a geração de resíduos, as mudanças climáticas, e, outros problemas como a dificuldade de acesso à saúde, à educação, ao saneamento básico, à produção, à segurança e soberania alimentar e tantos outros.

Com a ideia de que o progresso geraria uma vida com mais qualidade, segurança e trabalho para a população mundial o capitalismo vem expandindo uma estratégia de desenvolvimento que é destruidora do ambiente natural e, por consequência, dos seres humanos que são parte integrante deste último. Para Morin (1988), pensar os humanos como parte integrante da natureza implica percebê-la como totalidade, ou seja, um todo complexo, dinâmico e relacional do qual faz parte o ser humano, mas também os demais seres vivos,

"A natureza não é desordem, passividade, meio amorfo: é uma totalidade complexa. $\mathrm{O}$ homem não é uma entidade isolada em relação a essa totalidade complexa: é um sistema aberto, com relação de autonomia/dependência organizadora no seio de um ecossistema" (Morin 1988:11).

A produção de químicos sintéticos, que apresentam alto grau de toxidade e degradam o ambiente como plásticos, agrotóxicos e envenenam os solos, poluem as águas, lagos, rios, oceanos, levando à morte animais silvestres e adoecendo pessoas, nos mostram que a premissa adotada pelas abordagens desenvolvimentistas provoca exatamente $\mathrm{o}$ contrário das abordagens que primam pela co-evolução da sociedade e natureza evidenciando, desta forma, uma crise de percepção sobre 
os diferentes olhares dos problemas, e, estão interligados, de modo que a escassez dos recursos e a degradação do meio ambiente levam as comunidades locais ao colapso e à violência étnica (Capra 1996).

No caso da população das águas os diferentes processos de identificação com a natureza fazem parte da memória coletiva e são necessários à reprodução física, social e cultural do seu 'ser' na qualidade de pescadora e marisqueira. $\mathrm{O}$ modo de vida, que compreende um jeito particular de se relacionar com a natureza, faz parte da sua tradicionalidade. E, nesse aspecto, vale salientar que a colonização enquanto momento histórico, trouxe implicações tanto no âmbito cultural quanto no econômico e político, impondo o seu poder, limitando os subalternizados na busca de mudanças estruturais e que persiste até os dias atuais (Spivak 2010). E conforme assinala Paulo Freire (1967),

“[...] O Brasil nasceu e cresceu sem experiência de diálogo. De cabeça baixa, com receio da Coroa. Sem imprensa. Sem relações. Sem escolas. "Doente". Sem fala autêntica. [...] As sociedades a que se nega o diálogo - comunicação - e, em seu lugar, se lhes oferecem 'comunicados' resultantes de compulsão ou 'doação', se fazem preponderantemente 'mudas'. O mutismo não é propriamente inexistência de resposta. É a resposta a que falta teor marcadamente crítico" (Freire 1967:66-69).

O processo de mutismo que historicamente carregam as populações vulneráveis trouxe a relação colonial como um processo antagônico. Esse antagonismo aparece de forma determinante nos escritos de Ballestrin (2013), ao discorrer acerca da genealogia do pós-colonialismo. Nas palavras de Laclau \& Mouffe, o antagônico se faz sentir na medida em que a “presença do 'Outro' me impede de ser totalmente eu mesmo. A relação não surge de identidades completas, mas da impossibilidade de sua constituição", pois "[...] não posso ser uma presença completa para mim” (2001:125). Isto é, a construção da identidade e vocalização dela se retrai em uma imposição compulsória da identidade do colono, reprimindo e estruturando sua ressignificação a uma ótica de impossibilidade de expressar a si mesmo. 
○ós-colonialismo impactou em três âmbitos principais: político, cultural e intelectual segundo Ballestrin (2017). Essa autora assinala que as "tensões entre o poder, subjetividade, identidade, representação e conhecimento" são fundamentais para o entendimento do exercício do poder colonial, que "produz e reforça desigualdade específica e transversal àquelas relacionadas com classe, gênero e raça" (Ballestrin 2017:511).

Assim, construir um pensamento epistemológico novo, que resgate a lógica dos povos originários, incide, em alta escala, na capacidade de pensar em metodologias decoloniais de emancipação, de pensar em dialéticas diversas, ou seja, descolonizar o pensamento. É reinventar a "emancipação social indo mais além da teoria crítica produzida no Norte e das práxis social e política que ela subscrevera" (Santos 2006:27).

Em termos históricos, a expressão 'descolonial' indica a superação do colonialismo. Já a expressão 'decolonial' significa o oposto e procura transcender a colonialidade. E, sendo assim, cabe "salientar que a intenção não é desfazer o colonial ou revertê-lo”, ou seja, superar o momento colonial pelo momento pós-colonial (Colaço 2012:8). A intenção é provocar um posicionamento contínuo de transgredir e insurgir. Mais do que resistência, é a ação em si, ou seja, o decolonial implica, portanto, em uma luta contínua e o conhecimento científico deve, não apenas centrar-se no processo de saída do colono, mas na superação das suas marcas.

Para Frantz Fanon, o colonialismo é a negação sistemática do outro, mas não é somente a subjugação física de um povo por outro, pois incorpora um conjunto de elementos que tem como princípio a negação da diversidade, em favor de um determinado modo de comportamento, de pensamento, de produção. Ademais, a alienação colonial impossibilita o sujeito de se constituir enquanto sujeito da sua própria história, pois não basta mudar a visão de mundo, mas, sobretudo, "[...]transformá-lo" (Fanon 2008:33). Segundo Mignolo (2017), pensar acima de uma ótica colonizadora é nada menos que um ine- 
xorável esforço de análise para compreender a lógica do colonizador, por meio de uma retórica da modernidade a fim de, então, superá-la.

Diante disso, adotamos neste artigo uma definição ampla de decolonialidade e que não está restrito, a fim de apreendermos os processos de resistência e luta das mulheres marisqueiras e pescadoras artesanais pela garantia dos seus direitos, para a melhoria e qualidade de vida e condições de trabalho.

O início do diálogo com as marisqueiras e pescadoras artesanais da Ilha da Maré se deu, a priori, a partir de uma demanda social apresentada pela Articulação Nacional de Pescadoras (ANP) à Fundação Osvaldo Cruz (Fiocruz), cujas especificidades incluíam a ideia de um desenvolvimento do território em bases mais saudáveis e sustentáveis, visando a qualidade de vida dos seus moradores.

Para esta abordagem, a metodologia utilizada baseou-se na pesquisa-ação, na análise bibliográfica e documental, além de constituir diálogos individuais com as mulheres das águas durante o trabalho educativo realizado pela equipe interdisciplinar, no período de 2018 a 2019. A metodologia de pesquisa-ação,

“[...] é um tipo de pesquisa social com base empírica que é concebida e realizada em estreita associação com uma ação ou com a resolução de um problema coletivo e no qual os pesquisadores e os participantes representativos da situação ou do problema estão envolvidos de modo cooperativo ou participativo" (Thiollent 2009:16).

A pesquisa-ação, assim como as demais metodologias participativas de pesquisa, vem ganhando reconhecimento por se tratar de um processo que permite a colaboração dos sujeitos envolvidos e pesquisadores em todas as etapas da pesquisa. Isso implica antes de tudo, em se tratando de um estudo envolvendo uma colônia de pescadores, 'dar a voz' a quem de direito, ou seja, as mulheres marisqueiras e pescadoras, cujo protagonismo emerge na luta por direitos na Ilha. Contudo, nunca é demais ressaltar que para qualquer intervenção ou atividade a ser realizada em uma comunidade tradicional pesqueira é necessário o diálogo e aquiescência de toda comunidade local, no que diz respeito 
a sua cultura. Ou seja, para se fazer uma imersão nas águas e na lama, há que se ter e demonstrar respeito com as pessoas que ali estão, mas também com as marés, pois são elas que ditam se é possível ou não se aproximar da ilha.

A pesca artesanal é um conceito geral para todas as atividades realizadas na pesca. A mariscagem é uma destas atividades, que compõe a cadeia produtiva da pesca, sendo um diferencial importante, pois é exercida, em geral, por mulheres.

Cabe destacar que a pesca artesanal subsiste longe das indústrias pesqueiras, sendo uma atividade geradora de renda de muitas famílias e oportuniza o desenvolvimento econômico informal, além de manter uma atividade tradicional, o seu modo de vida e reprodução social.

A mariscagem não é um termo dado, pois foi construído como resultado das relações sociais. Trata-se de uma atividade que tem sido invisibilizada, cujo reconhecimento se deu a partir da percepção destas mulheres como agentes sociais, econômicos e políticos, que reforçam a sua identidade, seja na comunidade, seja fora dela, caracterizando assim, a desigualdade de gênero na definição jurídica, quando estas buscam seus direitos, a exemplo de benefícios previdenciários. Elionice Sacramento, liderança e pescadora artesanal, sintetizou de forma poética a identidade das mulheres das águas, das mulheres pescadoras artesanais, marisqueiras:

"[...] mulheres das águas do mar, da lama do mangue, das águas dos rios, lagoas e lagunas, dos costeiros lamosos, cascalhoso ou arenoso. Maré-Mulher: territórios feridos, violentados, atacados. São águas que sustentam o corpo da mulher e enriquece o território da maré Mulher, maré, águas, pescadora, extrativista, ribeirinha. [...] Corpos/costeiros atacados, desejados, privatizados. Eu, você, elas e nós Mulheres, marés, águas. Somos transformação, ação e muitas vezes emoção. Luta e resistência são nossos nomes e sobrenomes. Protagonismo e invisibilidade conflitam com a história. Nós somos mulheres das águas" (Sacramento 2019:52).

Uma população que se move pelos horários das marés, pela determinação da lua e dos ventos. Segundo Pena \& Martins (2014) a pesca artesanal, 
"Caracteriza-se total ou parcialmente por regime produtivo de subsistência com emprego de embarcações de médio e pequeno porte e equipamentos sem nenhuma sofisticação, não havendo, em geral, remuneração pelo trabalho desenvolvido [...] esta atividade representa modalidades de atividades milenares, originárias das formas mais tradicionais das sociedades humanas, pois sempre envolveu o uso de instrumentos simples de trabalho" (Pena \& Martins 2014:38-40).

A nossa abordagem aqui vincula a pesca artesanal e a mariscagem ao território, buscando compreendê-lo em suas especificidades e diversidades, a partir dos papéis desempenhados na inter-relação entre colonialidade e gênero no contexto da luta por direitos e defesa do território da pesca artesanal.

Cabe destacar a luta das mulheres das águas e como elas tecem o caminho, a fim de garantir os seus direitos, projetando para que as gerações futuras também tenham seus direitos garantidos. Da mesma forma, chama-se a atenção para a luta destas mulheres e como elas tecem o seu caminho, a fim de garantir os seus direitos, projetando para que as gerações futuras também tenham seus direitos garantidos.

\section{Território e identidade: trajetórias de luta das pescadoras artesanais}

A atual conjuntura política e econômica brasileira demonstra-se transgressora de direitos históricos, sejam eles sociais, ambientais, trabalhistas, territoriais, entre outros, resultando em perdas e desafios ao conjunto da população. A degradação dos ecossistemas, as disputas de territórios, a contaminação química, escoamento de esgotos, o impacto do derramamento do petróleo nas praias do litoral brasileiro, culminam por inviabilizar práticas tradicionais de extrativismo, manejo de recursos naturais, que são a base da reprodução social de comunidades tradicionais, entre elas, pescadores artesanais e quilombolas.

Neste sentido, a Carta Magna (1988) assinala o "direito ao meio ambiente ecologicamente equilibrado", e assim, impõe ao "poder público e à coletividade o dever de defendê-lo e preservá-lo para as presentes e futuras gerações" (Brasil 2016:131). 
Entretanto, isto não ocorre de fato, principalmente quando falamos de comunidades tradicionais, que ainda se encontram silenciadas por pressões econômicas, fundiárias e de exclusão social, ou seja, ainda se encontram na invisibilidade. A Política Nacional de Desenvolvimento Sustentável dos Povos e Comunidades Tradicionais, traz no seu escopo o reconhecimento identitário definindo-os como,

"Grupos culturalmente diferenciados e que se reconhecem como tais, que possuem formas próprias de organização social, que ocupam e usam territórios e recursos naturais como condição para sua reprodução cultural, social, religiosa, ancestral e econômica, utilizando conhecimentos, inovações e práticas gerados e transmitidos pela tradição" (Brasil 2007:1).

Assim, o território é o que mantém vivo a memória de um grupo, seu modo de produção e reprodução social, sua visão de mundo a partir do conhecimento local, que pode ser vivenciado, apreendido, portanto, é olhar a potencialidade desse território. Milton Santos (2006) reconhece o território, como território usado e constitui em alicerce de abordagem, o reconhecimento das heranças, e, ao mesmo tempo, o sentido pela população.

Portanto, esse território é gerador de identidade, de cultura, ou seja, um espaço habitado e utilizado por uma dada população, uma estrutura dotada de movimento próprio, que concebe uma visão ampla e plural de território. A abordagem de Santos (2006), ratifica esse território usado, vivenciado pelos pescadores artesanais como um território plural.

Além disto, o território pesqueiro traz um sentimento de pertencimento e que envolve uma mobilização em defesa deste território, a partir da identificação com o bioma e/ou ecossistema. E há também de se considerar a dimensão simbólica inscrita neste território, principalmente quando este e a sua memória social estão ameaçados. Pois, a territorialidade tem multiplicidade de expressões e consequentemente traz também especificidades socioculturais.

O território das águas, compreendido como um tecido social, contempla uma teia de reciprocidades sociais, encontrado nos víncu- 
los sociais, nos quais o parentesco assume um papel importante de usufruto de determinadas áreas em função do seu uso, de significados e conhecimentos pelos pescadores artesanais, fazendo parte da sua tradição. Isto fica evidente na fala de uma pescadora artesanal, para quem:

"[...] os territórios pesqueiros são ambientes aquíferos (rios, lagos, lagoas e mares) de valor singular mesmo sendo tão plural. As águas têm uma importância intangível para nós: sempre foi, entre outros aspectos, um lugar mais que sagrado, determinante de nossas relações, especialmente de sobrevivência, além de um espaço de fé e/ ou culto, manifestação da cultura, de recreação, trabalho, musicalidade, reabilitação e cura. Sempre vimos a água para além de sua forma química $\left(\mathrm{H}_{2} \mathrm{O}\right)$ ou função de hidratação do corpo, trata-se de um elemento cuja forma de medir valor deve considerar muitas variáveis, a expressão de sua importância pode ser classificada de modo holístico e está diretamente imbricada na boa saúde" (Sacramento 2015:139).

Portanto, esses territórios devem ser considerados de maneira multidimensional, o que significa conceber as formas de produção, apropriação e espaço social onde são construídas. De forma geral, "sua territorialidade funda-se na afiliação por parentesco, práticas culturais, coparticipação de valores e, em especial, por circunstância de solidariedade e reciprocidade" (Bandeira 1991:8).

E é precisamente com essa mesma perspectiva que cerca de 6.434 habitantes (IBGE 2010), uma população majoritariamente de pretos/ pardos, vive na Ilha de Maré, cujo o modo de vida, de produção e reprodução social, estão relacionados predominantemente com a água e com a terra. São marisqueiras, pescadores artesanais, artesãos de cestaria e rendas de bilro, que também praticam agricultura de subsistência.

A Ilha de Maré faz parte das 56 ilhas que compõem a Baía de Todos os Santos (BTS) e contempla pequenas comunidades na margem litorânea, denominadas: Bananeiras, Botelho, Caquende, Itamoabo, Maracanã, Martelo, Neves, Ponta Grossa, Porto dos Cavalos, Praia Grande e Santana. Cerca de 60\% do território da Ilha refere-se às comunidades quilombolas. 
O acesso à Ilha implica em um grande desafio, pois as vias de acesso se dão por meio de São Tomé do Paripe, Salvador ou dos Distritos de Passé e Caboto, ambos de difícil percurso, pertencentes ao município de Candeias. As embarcações na sua maioria são de pequeno porte e a motor. Análogo, no interior da ilha não existem carros tampouco transporte público, de modo que a locomoção das pessoas e de cargas se dá por meio de cavalos, bicicletas e carros de mão.

$\mathrm{Na}$ Ilha há apenas um posto de saúde e três escolas, que atendem o ensino fundamental. Há também uma creche construída pela comunidade para atender as crianças das pescadoras. Não tem saneamento básico, há apenas valetas que direcionam o material de esgoto sem tratamento, sendo parte para os mangues e parte para o mar. Animais e pessoas circulam no meio destas valetas e a vida continua. Daí porque conhecer a Ilha de Maré, sua população, seu modo de vida, as marés, significa antes de tudo voltar o olhar à conjuntura histórico-social que moldou as disparidades deste tempo, ainda mais quando se trata de pescadores artesanais, marisqueiras e quilombolas, ou seja, de uma população negligenciada, invisível aos olhos do Estado e à margem das políticas públicas.

A BTS conta com uma expressiva extensão de recifes de corais, estuários e manguezais e forte relação com a história do Brasil, uma vez que Salvador - BA foi a primeira capital da colônia portuguesa, bem como abrigou um dos maiores portos exportadores do Hemisfério Sul, inclusive sendo um dos que mais receberam escravizados.

$\mathrm{O}$ 'desenvolvimento' traçado por séculos e o crescimento da região, conforme assinalam Hatje \& Andrade (2009), fizeram com que a BTS tivesse potencial para instalação de terminais portuários de grande porte, visto ser um canal de entrada naturalmente navegável, com canais internos profundos, que facilitam a exportação de alguns produtos, bem como, a importação de outros. Como resultado de todo este processo, o entorno da BTS compreende, atualmente, uma extensa zona industrial que inclui o maior polo petroquímico do hemisfério sul, o Porto de Aratu. 
O Porto de Aratu contempla mais de 200 indústrias entre químicas, metalúrgicas, siderúrgicas, mecânicas, farmacêuticas e alimentícias, além das instalações petrolíferas e portuárias, chaminés, dutos, tanques para estocagem de insumos e derivados, terminais portuários com píeres de atracação, cais, cargueiros e petroleiros entre outras estruturas. Esse complexo, responsável por $60 \%$ da carga movimentada em modal marítimo da Bahia, bem como é considerado de grande importância para a economia da Bahia (Carvalho 2014). Porém, ao mesmo tempo, traz grandes impactos à população da BTS. E por estar mais próxima a este complexo, a população da Ilha de Maré é quem mais sofre com os efeitos dessa ação antrópica.

Por conta disso a população da Ilha de Maré vem denunciando há décadas o impacto do complexo do Porto de Aratu no ambiente, no trabalho e na saúde da sua população. Pois, conforme assinala Carvalho (2014), a contaminação das águas, dos mangues e animais marinhos repercute diretamente sobre o trabalho da pesca artesanal e da mariscagem e, consequentemente, afeta o sustento das famílias. $\mathrm{Na}$ opinião desse autor a comunidade demanda por uma ciência que se preocupe em estudar a contaminação ambiental e ratificar que isso afeta não só o ambiente, mas a saúde de uma população inteira e, portanto, atinge diretamente o exercício do trabalho e a subsistência dos moradores da Ilha e, concomitantemente, a saúde e a vida da população das águas.

Os mangues, partes constitutivas dos ecossistemas da Ilha da Maré, são considerados como celeiros da vida marinha, pois seus recursos são empregados como fonte de proteína e renda para as populações das águas, conforme já mencionado por Josué de Castro ainda na década de 1940,

"O mangue abriga e alimenta uma fauna especial, formada principalmente por crustáceos, ostras e caranguejos, numa impressionante abundância de seres que pululam entre suas raízes nodosas e suas folhas gordas, triturando materiais orgânicos, perfurando o lodaçal e umidificando o solo local. Muitos desses pequenos animais contribuem também com suas carapaças e seus esqueletos calcários, para 
a estruturação e consolidação do solo em formação. Desempenha também essa fauna especializada um importante papel no equilíbrio ecológico da região ocupada pelo homem, ao possibilitar recursos de subsistência para uma grande parte das populações anfíbias que povoam aqueles mangues" (Castro 1948:23).

Por isso, é quase impossível dissociar o homem da natureza, pois "toda relação humana é uma relação natural, toda relação com a natureza é uma relação social” (Derani 1997:149-150). Esse é o caso da população das águas que tem uma ligação intimamente ligada ao mundo natural aquático, pois "vivem quase que dentro d'água [...] nos mangues, [...]" não são "nem da terra, nem da água [...]”, mas são ao mesmo tempo a "mistura desses dois elementos" (Castro 1992:150).

A pesca artesanal e a mariscagem são atividades milenar, sendo esta última exercida essencialmente por mulheres, embora a forma de vida social é compartilhada por todos e não impede que homens também possam realizar esta atividade. Observa-se que o processo de trabalho realizado por estas mulheres é muito intenso, na maioria das vezes leva de 10 a 14 horas, entre o acordar, os preparativos para a saída, o trajeto, a coleta, o beneficiamento e a comercialização (Pena $\&$ Martins 2014).

O material utilizado pelas marisqueiras é rústico, pois são apetrechos fabricados por elas próprias, tais como: colheres, iscas encontradas no próprio ambiente dos mangues e nas matas próximas aos locais de pesca, construção de armadilhas para captura de aratu, siri, entre outros. Isto é, trata-se de materiais que fazem parte da tradição dos pescadores artesanais, um saber particular construído pela experiência, além de preservarem este ambiente.

Ademais, a pesca artesanal utiliza a arte de captura de pequeno porte, o que reduz os danos físicos aos ecossistemas, face, a diversidade de modos de pesca/mariscagem e estratégias de subsistência. Assim, a pesca artesanal praticada na Ilha da Maré apresenta-se como uma modalidade mais sustentável do que a pesca empresarial, pois as pessoas que lá vivem, também lá trabalham, produzem, consomem e 
de lá retiram seu sustento. Daí a necessidade de se repensar a atividade pesqueira na Ilha tendo em conta seus aspectos políticos, sociais, econômicos e ecológicos, ou seja, imprimindo ao âmbito da pesca um enfoque sistêmico.

Contudo, há que se considerar também "a inter-relação entre estes aspectos que produzem configurações emergentes, que podem 'amplificar' efeitos secundários não imaginados" (Pasquotto \& Miguel 2004:5). Isso implica, necessariamente, o reconhecimento das conexões entre os diferentes elementos do sistema, com vistas a valorização das formas de organização e do trabalho e remuneração, bem como a preservação dos recursos naturais. Na prática, essa abordagem pressupõe um manejo integrado da pesca, no qual múltiplos fatores devem ser observados, tanto naturais quanto antrópicos.

É a maré que demarca o tempo para mariscar, ocorrendo a mariscagem quando a maré vaza e, quando isso acontece, os mangues se alargam, ficando bastante visíveis. Nesse momento as mulheres entram literalmente na lama para fazer o extrativismodos mariscos. E ali permanecem agachadas durante horas até capturar o máximo possível de 'frutos' do mar. E quanto maior for a quantidade capturada, maior é a remuneração do ponto de vista econômico, mas com consequências, e em certos casos, graves para a saúde das mulheres.

Outrossim, a participação política das mulheres no âmbito da pesca artesanal alterou nos últimos anos, principalmente ao tomarem consciência da condição de invisibilidade a que estavam submetidas e assumirem a condição de marisqueiras e pescadoras artesanais. Contudo, como assinala Sacramento,

"A invisibilidade não é o único problema imposto às mulheres negras, mas ela nos tem causado grandes prejuízos, visto que não se garante direitos para quem não existe ou não é vista" (Sacramento 2019:56).

Mas, ao se mobilizarem e se organizarem passaram a romper com a invisibilidade e garantir os seus direitos. Fato é que as mulheres estão à frente da organização nas colônias de pescadores, papel antes 
presidido por homens pescadores. Esse é o caso da Colônia de Pescadores da Ilha de Maré, que é presidida por uma marisqueira, que rompe com a tradição patriarcal, assim como muitas outras mulheres pescadoras, passando a presidir a Colonia de Pescadores Z-4. Imprimindo a sua gestão um caráter mais participativo, uma vez que a Colônia atual, é coordenada por uma gestão colegiada, que conta com a participação de lideranças de todas as comunidades da Ilha.

$\mathrm{E}$ aos poucos, estas mulheres vão conquistando seus espaços, seja reivindicando reconhecimento enquanto marisqueiras, seja na luta pelo seguro defeso ${ }^{2}$ e aposentadoria, entre outros direitos. Não obstante, outras frentes de luta têm exigido maior empenho, face a retirada de direitos, duramente conquistados, inclusive o direito à mariscagem, que só pode continuar sendo realizada se o ambiente for efetivamente preservado.

Não obstante, a perspectiva decolonial se estende às questões de gênero, cuja a luta por direitos é uma constante na Ilha, bem como para dar visibilidade às mulheres pescadoras e marisqueiras numa atividade que ainda se encontra estruturalmente masculinizada. E, se assim o é, cabe perguntar: é possível lançar uma defesa do lugar, para quem o lugar também é opressivo? Isso nos remete ao conceito de colonialidade de gênero, que nos permite pensar em seres históricos compreendidos apenas de forma unilateral. Na verdade, "a mulher se encontra duplamente na obscuridade” (Spivak 2010:71). Essa duplicidade está no fato de que na historiografia colonial foi reforçada a ideia de dominação masculina pelo modelo patriarcal, que perpassa pela própria constituição estrutural de Estado Nação. Ou seja, o poder do patriarcado tem "influenciado as ideias mais básicas acerca da natureza humana” (Spivak 2010:67). Consequentemente, o território para as pescadoras artesanais é compreendido como espaço necessário para reprodução social, cultural, econômica, sendo a base para a sua identidade. Um espaço de crenças, de mitos e utopias.

Portanto, a perspectiva descolonial não remete a um universalismo abstrato, mas sim ao diálogo entre os múltiplos projetos críticos, 
epistêmicos, éticos. Instiga a refletir sobre as mudanças sociais de uma forma não diminutiva, mas compreende-la para a ação, pois continuamos a viver a mesma matriz colonial, de exploração, de dominação. Os saberes subalternizados são silenciados, ignorados ou mesmo omitido conforme o processo de produção/reprodução do conhecimento. Saberes esses, que se situam na interseção do tradicional e do moderno, como afirma Mignolo (2017).

Assim, as várias formas de resistência das mulheres da pesca artesanal, que precisam serem reinventadas cotidianamente, reinvestidas de simbolismo, fazendo as suas demandas serem escutadas. $\mathrm{O}$ desafio é incorporar os saberes subalternizados nos processos de produção de conhecimento e, portanto, criar novos espaços, a partir dos quais possam falar e serem escutados. Portanto, a relação com a natureza, com a conservação do seu ecossistema, vai além do pescar, do mariscar. Estão intrinsecamente conectados, pois trazem uma singularidade para o olhar que têm sobre seu território, ao grupo que ali vive e que ali se identifica, criando uma linguagem toda própria e que é passada, de pai/mãe para filho(a), por meio da oralidade, por meio da observação da natureza, do mar, do vento, da lua que ajudam nos afazeres do seu dia-a-dia.

\section{Mulheres, marisqueiras, pescadoras artesanais}

As mulheres marisqueiras - pescadoras artesanais da Ilha de Maré estão à frente da organização da colônia de pescadores e impõem uma dinâmica própria a vida na comunidade. São protagonistas da luta pelo território, realizam reuniões, nas quais tomam decisões e deliberam sobre as ações voltadas ao bem-estar da comunidade. Enfim, possuem um espaço onde compartilham as dificuldades, os problemas, a fim de conjuntamente solucioná-los. Além disso, ao se reunirem, compartilham informações sobre os diversos assuntos de interesse tanto pessoais quanto da coletividade em que a troca de conhecimentos e experiência é a regra e não a exceção. Entretanto, as mulheres da Ilha enfrentam cotidianamente o medo, resultante do impacto da conta- 
minação advindo do Porto de Aratu sobre a saúde, o ambiente e o trabalho. Conforme aponta Boaventura de Sousa Santos,

O seu riquíssimo ecossistema tem sido destruído desde os anos de 1960 pela poluição causada pelas indústrias e empresas multinacionais construídas em volta da zona de operação portuária do Complexo de Aratu, a poucos quilômetros da ilha. [...] ondas de fumaça residuais pestilentos expelidas sem filtros e trazidas pelo vento, carga e descarga dos navios de minérios e produtos químicos altamente tóxicos sem qualquer precaução acabando por se espalhar no ar (enxofre e gases de amônia) [...] no solo e nas águas, arsênio, cádmio, chumbo, cobre, cromo, ferro, mercúrio e zinco (Santos 2018:1).

Isso tem comprometido sobremaneira a saúde da população, a produção e o seu modo de vida. Da Ilha sai o 'sangue preto' da terra, mas ficam os vestígios da parafernália tecnológica das plataformas, cujas tubulações usadas na extração são imediatamente abandonadas quando seca a última gota de petróleo.

E mesmo que as empresas derrubem a plataforma tão logo finalizem o processo de extração, parte das estruturas ainda fica causando danos ao ambiente e ao trabalho dos pescadores, danificando redes e causando acidentes. A população denuncia, mas a voz é silenciada pelo sistema de poder estatal advindo do complexo de Aratu. Pois, o alarido ecoa da 'terra de preto', uma população ainda invisibilizada, empobrecida economicamente e subjugada em suas cosmovisões.

Mas, em que pese a disposição e a resistência da população da Ilha isso tudo torna perceptível, num sentido mais amplo, que a colonialidade do poder inaugurou um novo sistema de dominação social determinado pela ideia de raça, que articulada de forma dialética com o sistema de exploração social capitalista que enfim, contribuiu para as diversas falhas e descontinuidade do processo de nacionalização e democratização do Estado e da sociedade. Pois, numa situação como esta, "como seria possível recorrer ao amparo dos direitos estatais, [...] cujo projeto histórico não coincide com o projeto do tecido comunitário?" (Segato 2012:110). 
E, se na mesma medida o Estado, paradoxalmente, é o primeiro a violar os direitos da população desta comunidade? E, ainda, como pensar em direitos de uma maneira mais ampla se a essa população são negados os direitos mais fundamentais como a saúde, saneamento, entre outros?

fato é que a população da Ilha é silenciada também quando suas demandas não são atendidas, quando as políticas públicas não chegam, quando o acesso à saúde falta, quando o ambiente é poluído, e, consequentemente, diminuindo o pescado que compromete o seu meio de subsistência. Não obstante, a decisão de não desistir e continuar a luta faz com que essas mulheres ecoem sua voz, em defesa da pesca artesanal e das comunidades tradicionais pesqueiras e em resistência contra o 'latifúndio das águas e das terras', como afirmam as palavras de luta impressas em seu manifesto: "É no rio e no mar! Pescador na luta! No açude e na barragem: pescando a liberdade! Hidronegócio: resistir! Cerca nas águas: derrubar!” (CPP 2010).

Um ato de resistência e como Lugones afirma, descolonizar o gênero é necessariamente uma práxis, uma transformação vivenciada do social, afinal o "feminismo não fornece apenas uma narrativa da opressão de mulheres", vai além da opressão ao fornecer materiais que permitem às mulheres compreender sua situação sem sucumbir a ela (Lugones 2014:940).

As mulheres pescadoras artesanais/marisqueiras têm protagonizado o debate nos mais diversos espaços, visando com isso, construir ações efetivas à melhoria da qualidade de saúde e trabalho na pesca artesanal. E todos os caminhos para a garantia da saúde como direito, têm passado pela organização das mulheres. Apesar das dificuldades internas que precisavam lidar.

A lida dos afazeres domésticos, o cuidado com os filhos, a mariscagem, as experiências individuais, fizeram essas mulheres a se reunir em espaços, onde sem a interferência masculinas, essas mulheres podiam se expressar e tornava-se possível a troca de experiências. As relações estabelecidas fortaleciam as mulheres e novas demandas surgiam 
dessas experiências, como a criação de creches, melhoria do ambiente, do trabalho, se organizavam para irem sempre em grupo para mariscar, evitando assim, violências externas.

Dentre as principais demandas sociais das pescadoras artesanais está o reconhecimento de sua profissão pelo Instituto Nacional de Seguridade Social (INSS). As mulheres pescadoras relatam que o Estado não está aceitando a carta da Colônia de Pescadores, pagam a Colônia visando terem direitos reconhecidos, porém a realidade é outra, pois enfrentam discriminação e a negação.

Ao requererem o benefício, não têm garantido nenhum direito trabalhista, como por exemplo, a licença-maternidade, direito de todas as trabalhadoras e senso comum nas falas das marisqueiras, para tentar justificar a não aprovação, conforme escuta em uma reunião de trabalho, a fala da pescadora traz a sua indignação - "acho que a gente tem que ir toda suja de lama para provar a profissão, quem sabe assim, eles acreditam" e essa situação traduz a expressão de sujeitos coletivos, na busca da cidadania. Um outro problema apontado pelas pescadoras artesanais é a contagem do tempo para aposentadoria especial, da qual faz jus, mas não as mulheres trabalhadoras da pesca. Nessa discussão, o papel da Colônia de Pescadores na construção de uma identidade profissional da pesca artesanal e o reconhecimento das mulheres pescadoras é fundamental.

Nas lidas diárias as pescadoras artesanais têm longas jornadas de trabalho. Isso tem acometido as mulheres de algumas doenças decorrentes do trabalho, como lesões por esforços repetitivos (LER), dermatites, rinite e até câncer. $\mathrm{O}$ acesso às ações e serviços de saúde é uma outra barreira que precisa ser vencida. Solicitam que no Sistema de Informação em Saúde do Sistema Único de Saúde (SUS) tenha a identificação de 'pescadora', assim, os gestores e trabalhadores da saúde poderiam compreender a particularidade do processo saúdedoença que acomete a população das águas (Pena \& Martins 2014).

Dentre outras demandas apresentadas pelas mulheres estão: a revisão da instrução normativa (MPA nº 6, de 16 de abril de 2010) 
que igualou a pesca artesanal com a industrial em relação às licenças; agilização para a liberação do seguro defeso, atualização da lista sobre doenças relacionadas ao trabalho da pesca e outras questões trabalhistas e previdenciárias. As mulheres demandam ainda, a implementação da Política Nacional de Saúde Integral das Populações do Campo, da Floresta e das Águas cujo objetivo é a melhoria da qualidade de vida dessas populações e o acesso às ações e serviços de saúde no país.

Enfim, todas estas são demandas que por certo também fazem parte das bandeiras de lutas levantadas, de forma mais ampla, pelo conjunto dos movimentos sociais da pesca, que se ocupam de chamar atenção para às diversas dificuldades enfrentadas pelos pescadores artesanais, pois a invisibilidade e a negação de direitos, também fazem parte do dia a dia dessas populações. Além disto, a condição das mulheres marisqueiras, pescadoras artesanais e quilombolas da Ilha de Maré, revela de forma especial e emblemática as especificidades e diversidades das mulheres das águas que exigem medidas também específicas e diversas voltadas para a melhoria da qualidade de vida da sua comunidade.

A luta pela sobrevivência, pelo território, faz com que a população da Ilha, em especial, as mulheres, denunciem e exijam que seus direitos básicos sejam garantidos e que seus recursos naturais não sejam depredados.

Vale salientar que refletir as lutas históricas das mulheres das águas é antes de tudo reconhecer a força e a luta que as move para a garantia dos seus direitos, na defesa do seu território, como cidadãs e como mulheres. Mas sem perder de vista o fato de que somente a sociedade como um todo, em suas lutas históricas mais amplas, pode alterar e transformar radicalmente a realidade em que se vive, construindo suas modalidades de proteção social e sua condição de cidadania.

\section{Breves considerações}

As mulheres têm uma especial contribuição histórica no campo, nas florestas, nas águas. Ao buscarem direitos, as mulheres pescadoras 
artesanais, não estão apenas reivindicando direitos para si próprias, mas a toda categoria, pois ao enfrentarem o discurso hegemônico sobre os direitos sociais e políticos na sociedade, reafirmam a comunidade a qual pertencem.

A população da Ilha da Maré ainda tem um longo caminho a ser percorrido, em face da expansão do capitalismo, que está fortemente materializado no Complexo Industrial de Aratu e sem demonstrar a possibilidade de reverter minimamente os impactos ao meio ambiente, principalmente o impacto ao território, a saúde e ao trabalho desta população. Afinal, se as empresas capitalistas que causam danos irreparáveis à natureza tivessem que indenizar adequadamente as externalidades por elas mesmas criadas, elas seriam inviáveis financeiramente.

Portanto, na tentativa de visibilizar às populações das águas e a sua história, é reconhecer o seu modo de produção e reprodução social, muitas vezes silenciados pela matriz colonial do poder. É reconhecer o potencial do processo de transmissão cultural entre gerações que reforça e ajuda a manter sempre presente a ideia da possibilidade da ação transformadora dessa realidade social.

Vale destacar, que a luta por reconhecimento social marca a trajetória dos pescadores artesanais, e, em especial, as marisqueiras, sem um contrato formal de trabalho e sem uma entidade que mediasse seus interesses, os pescadores ficavam a margem dos direitos trabalhistas e previdenciários por mais tempo que outras categorias de trabalho.

Contudo, é necessário explicitar que o olhar aqui compartilhado se fez a partir da observação de quem acompanha a resistência das populações das águas, mas que por sua natureza é limitado. E, nessa mesma linha de raciocínio, tampouco houve a pretensa intenção de entoar a voz ou assumir o papel das mulheres pescadoras, cuja luta deve resultar de sua própria disposição e capacidade de organização e enfrentamento, bem como do seu protagonismo cotidiano e coletivamente construído. 
Isso implica, necessariamente, numa perspectiva de estudo que abarque uma compreensão mais profunda das conjunturas que se entremeiam às mulheres deste território, o que significa dizer que esta reflexão não se finda aqui, apenas estabelece os primeiros olhares sobre as relações de poder, com atenção especial para o desenvolvimento deste Estado predatório sob o território e os corpos que nele produzem e vivem.

Portanto, a luta das mulheres marisqueiras na construção de um mundo mais equânime se dá em todos os espaços, desde os seus lugares de vida, aos seus territórios. Defendem o território pesqueiro, a pesca artesanal, o reconhecimento da mulher marisqueira e ressignificam com suas experiências o saber ancestral.

Por fim, quanto mais vozes se somam a essa luta, mais forte e resistente se torna.

\section{Notas:}

1 Harkot-de-la-Taille \& Santos (2012) fazem distinção entre os vocábulos escravo e escravizado. Ser escravo remete a permanência e estar escravizado a transitoriedade. O termo escravo designa um sujeito em disjunção com o querer e, consequentemente, com o poder agir, pensar e até viver por si. Éstar escravizado instaura tensão entre a continuação e mudança de condição. Nesse sentido nos perguntamos: subalterno ou subalternizado? De acordo com o dicionário Caldas Aulete subalterno significa subordinado, submisso e subalternizado aquele que se subalternizou; se tornou subalterno.

2 É um benefício pago ao pescador artesanal, que fica proibido de exercer suas atividades durante o período de defeso de alguma espécie, conforme previsto pela Lei no 10.779/2003, que dispõe sobre a concessão do benefício de seguro-desemprego, ao pescador artesanal durante o período do defeso. Art. $1^{\circ}$. O pescador profissional que exerça sua atividade de forma artesanal, individualmente ou em regime de economia familiar, ainda que com o auxílio eventual de parceiros, fará jus ao benefício de seguro-desemprego, no valor de um salário-mínimo mensal, durante o período de defeso de atividade pesqueira para a preservação da espécie.

\section{Referências:}

AULETE, C. 2020. Dicionário contemporâneo da língua portuguesa Aulete digital. (www.aulete.com.br; acesso em 23/06/2020). 
BALLESTRIN, L. 2017. "Modernidade/colonialidade sem 'imperialidade'? O elo perdido do giro decolonial". Dados - Revista de Ciências Sociais, 60(2):505-540.

. 2013. "América Latina e o giro decolonial". Revista Brasileira Ciência Politica, 11:89-117.

BANDEIRA, M. 1991. "Terras negras: invisibilidade expropriadora". Textos e debates, 1(2):7-24.

BRASIL, 2016. Constituição da República Federativa do Brasil: texto constitucional promulgado em 5 de outubro de 1988, com as alterações determinadas pelas Emendas Constitucionais de Revisão nos 1 a 6/94, pelas Emendas Constitucionais nos 1/92 a 91/2016 e pelo Decreto Legislativo no 186/2008. Brasília: Senado Federal/ Coordenação de Edições Técnicas.

2007. Decreto $n^{\circ} 6040$, de 7 de fevereiro de 2007, que institui a Política Nacional de Desenvolvimento Sustentável dos Povos e Comunidades Tradicionais. Brasília: Ed. Ministério da Saúde.

. 2013. Politica Nacional de Saúde Integral das Populações do Campo, da Floresta e das Águas. Brasília: Ed. Ministério da Saúde.

.2010. Instrução Normativa MPA no 6, de 16 de abril de 2010,o qual estabelece normas e procedimentos para a inscrição de pessoas físicas no Registro Geral da Atividade Pesqueira - RGP nas categorias de Pescador Profissional e de Aprendiz de Pesca. Brasília: Ministério da Pesca e Aquicultura - MPA.

CAPRA, F. 1996. A teia da vida: uma nova compreensão científica dos sistemas vivos. São Paulo: Cultrix.

CARVALHO, I. et al. 2014. "Por um diálogo de saberes entre pescadores artesanais, marisqueiras e o direito ambiental do trabalho". Ciênc. Saúde coletiva, 19(10):4011-4022.

CASTRO, J. 1992. Geografia da fome: o dilema brasileiro: pão ou aço. Rio de Janeiro: Gryphus.

1948. Fatores de localização da cidade do Recife: um ensaio de geografia urbana. Rio de Janeiro: Imprensa Nacional.

CPP. 2010. Carta do movimento dos pescadores e pescadoras artesanais. Santo Amaro - BA. (https://cppnorte.wordpress.com/carta-do-movimento-dospescadores-e-pescadoras-artesanais/; acesso em 23/06/2020).

COLAC̣O, T. 2012. Novas Perspectivas para a antropologia jurídica na América Latina:o Direito e o pensamento decolonial. Florianópolis: Fundação Boiteux.

DERANI, C. 1997. Direito ambiental econômico. São Paulo: Max Limonad.

FANON, F. 2008. Peles negras, máscaras brancas. Salvador: Edufba.

FREIRE, P. 1989. A importância do ato de ler em três artigos que se completam. São Paulo: Autores Associados/Cortez. . 1967. Educação como prática de liberdade. Rio de Janeiro: Paz e Terra.

GRAMSCI, A. 1977. Quaderni del cárcere. Turim: Einaudi. . 1978. Concepção dialética da história. Rio de Janeiro: Civilização Brasileira. 
HARKOT-DE-LA-TAILLE, E. \& SANTOS, A. 2012. "Sobre escravos e escravizados: percursos discursivos da conquista da liberdade". Trabalho apresentando no Simpósio Nacional Discurso, Identidade e Sociedade, 3, Campinas-SP. (www.iel.unicamp.br/sidis/anais/pdf/HARKOT_DE_LA_ TAILLE_ELIZABETH.pdf; acesso em 23/06/2020).

HATJE V. \& ANDRADE, J. (eds.). 2009. Baía de Todos os Santos: aspectos oceanográficos. Salvador: EDUFBA.

Instituto Brasileiro de Geografia e Estatística. 2019. Estados. Bahia. (www.ibge. gov.br/estadosat/perfil.php?sigla=ba\#; acesso em 12/10/2019).

LACLAU, E. \& MOUFFE, C. 2001. Hegemony and socialist strategy: towards a radical democratic politics. Londres/New York: Verso.

LUGONES, M. 2014. "Rumo a um feminismo descolonial”. Estudos Feministas, 22(3):935-952.

MBEMBE, A. 2018. Necropolítica: Biopoder, soberania, estado de exceção, política de morte. São Paulo: N-1 Edições.

MIGNOLO, W. 2017. "Colonialidade: o lado mais escuro da modernidade". Revista Brasileira de Ciências Sociais, 32(94):1-18.

MORIN, E. 1988. O paradigma perdido: a natureza humana. Portugal: Publicações Europa-América.

PASQUOTTO, V. \& MIGUEL, L. 2004. "Pesca artesanal e enfoque sistêmico: uma atualização necessária”. Trabalho apresentado no Encontro da Sociedade Brasileira de Sistemas de Produção, 6, Aracaju-SE.

PENA, P. \& MARTINS, V. (eds.). 2014. Sofrimento negligenciado: doenças do trabalho em marisqueiras e pescadores artesanais. Salvador: Edufba.

RIBEIRO, D. 2017. O que é lugar de fala?. Belo Horizonte: Letramento.

SACRAMENTO, E. 2019. Da diáspora negra ao território das águas: ancestralidade e protagonismo de mulheres na comunidade pesqueira e quilombola Conceição de Salinas-BA. Dissertação de Mestrado. Brasília: Universidade de Brasília. . 2015. "Água: ambiente livre para saúde dos pescadores e pescadoras do Brasil”. In Brasil (ed.): Saúde e ambiente para as populações do campo, da floresta e das águas, pp. 139-154. Brasília: Ed. Ministério da Saúde.

SANTOS, B. 2018. "Da ilha de Maré a outro mundo possível”. Outras palavras. (https://outraspalavras.net/pos-capitalismo/boaventura-da-ilha-da-mare-aoutro-mundo-possivel/; acesso em 12/10/2018).

SANTOS, M. 2006. O Brasil, território e sociedade no início do sec. XXI. Rio de Janeiro: Record.

SANTOS, V. 2018. "Notas desobedientes: decolonialidade e a contribuição para a crítica feminista à ciência”. Psicologia $\mathcal{E}$ Sociedade, 30:1-11.

SEGATO, R. L. 2012. "Gênero e colonialidade: em busca de chaves de leitura e de um vocabulário estratégico descolonial”. E-cadernos CES [Online], 18:106-131. 
SPIVAK, G. C. 2010. Pode o subalterno falar?. Belo Horizonte: Editora UFMG. THIOLlENT, M. 2009. Metodologia da pesquisa-ação. São Paulo: Cortez.

\begin{abstract}
The aim of this study was to reflect on the role of artisanal fisherwomen on Ilha de Maré, located in the Baia de Todos-os-Santos, belonging to the municipality of Salvador - BA. The fight in defense of its territory and the rights to a healthy environment, working conditions and quality of life takes place in a hostile scenario, due to exposure to the Complexo Industrial do Porto de Aratu. This led us to an approach in the light of the decolonialization of the water population, using a methodology based on action research, bibliographic survey and dialogues with women from the waters.
\end{abstract}

Keywords: Decoloniality, Rights social, Social struggles, Women of the waters.

Recebido em setembro de 2020.

Aprovado em março de 2021. 